\title{
Numerical Simulation Study of the Influence of Ceiling Materials to Roof Radiation Heat Exchange
}

\author{
Songtao Hu, Feng Qi , Teng Xie,Xinxin Wang,Gang Wang and Guodan Liu \\ Institute of Environmental\&Municipal Engineering, Qingdao Technological University, \\ Qingdao, 266033, China \\ E-mail: qfsummit@163.com
}

\begin{abstract}
This article focuses on the study of the influence of ceiling materials to roof radiation heat exchange by CFD numerical simulation, which provides a theoretical basis for the choice of ceiling materials from the perspective of thermal properties.

Keywords- CFD numerical simulation, Roof radiation heat exchange, Ceiling materials, Thermal physical properties Preface
\end{abstract}

\section{INTRODUCTION}

During interior design, people usually appropriate decorative ceiling to the top surface of the room. For airconditioned room with roof radiant cooling system, if not set the ceiling, and the installation of lighting tends to damage the coils in the ceiling structure, Therefore, the class room usually set a ceiling lamps installed in the ceiling at the reserved position.

Currently, study on radiant cooling is mostly concentrated in the influence of roof structure to roof heat exchang $^{[2][5]}$, the radiation board structure and properties ${ }^{[4]}$ ${ }^{[7]}$, the roof radiant cooling system heat transfer process ${ }^{[1][6]}$ ${ }^{[8]}$ and radiant cooling room indoor thermal comfort ${ }^{[3]}$ and so on, while the influence of ceiling materials to roof radiation heat exchange has not been studied.

Therefore, we select three kinds of ceiling materials: fiberboard, gypsum board and aluminum alloy plate, which are usually used in interior design, to study of the influence of ceiling materials to roof radiation heat exchange by CFD numerical simulation, which provides a theoretical basis for the choice of ceiling materials from the perspective of thermal properties.

\section{THE ESTABLISHME}

\section{A. Introduction to the simulated room}

The size of the room is $6200 \times 2200 \times 2850 \mathrm{~mm}(\mathrm{~L} \times \mathrm{W}$ $\times \mathrm{H}$ ) , the size of ceiling material is $6200 \times 1100 \times 10 \mathrm{~mm}$ $(\mathrm{L} \times \mathrm{W} \times \mathrm{T})$, and the room's clear height is $2600 \mathrm{~mm}$. The material of the wall is solid brick, the thickness of the external walls is $240 \mathrm{~mm}$, the thickness of interior walls and floor and ceiling is $120 \mathrm{~mm}$. The room has an exterior wall and three interior walls, and at the same time the inside and outside surfaces of the wall are brushed paint. There is a $1200 \times 1000 \mathrm{~mm}$ window in the exterior wall.

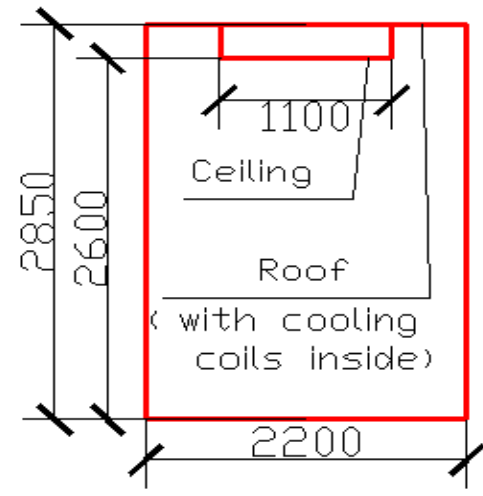

Figure 1. The schematic diagram of room size

\section{B. Set the basic assumptions and establish the physical model}

- $\quad$ Set the basic assumptions

Room of radiation heat transfer process can be regarded as the problem of radiation heat transfer between the various gray in the closed cavity, can be solved by using numerical method. In order to facilitate the simulation of the room, so provides the following basic assumptions: The surface of the roof radiation is isothermal surface, and the constant temperature is $23^{\circ} \mathrm{C}$. The absorption rate and the emission rate of the respective surfaces involved in the radiation heat transfer are the fixed value, and do not changes with temperature change. The air is as the medium, and the radiation is completely penetrated .The interior walls are considered adiabatic. Ceiling materials are isotropic, and the absorption rate and the emission rate of ceiling materials are the fixed value.

- $\quad$ Establish the physical model

The air-conditioned outdoor dry bulb temperature is $29^{\circ} \mathrm{C}$ of Qingdao in summer. There are two $75 \mathrm{w}$ heats still human in the room and there are four lamps in the ceiling, their spacing is $1000 \mathrm{~mm}$, and the power is $50 \mathrm{~W}$. Emissivity of the wall is 0.9 , the thermal conductivity of solid brick, aluminum alloy, hardwood, and gypsum is $0.7 \mathrm{w} / \mathrm{m} \cdot \mathrm{k}, 164$ $\mathrm{w} / \mathrm{m} \cdot \mathrm{k}, 1.0 \mathrm{w} / \mathrm{m} \cdot \mathrm{k}, 0.43 \mathrm{w} / \mathrm{m} \cdot \mathrm{k}$. The physical model established in accordance with the ratio of 1:1 by AirPak Software is shown below: 


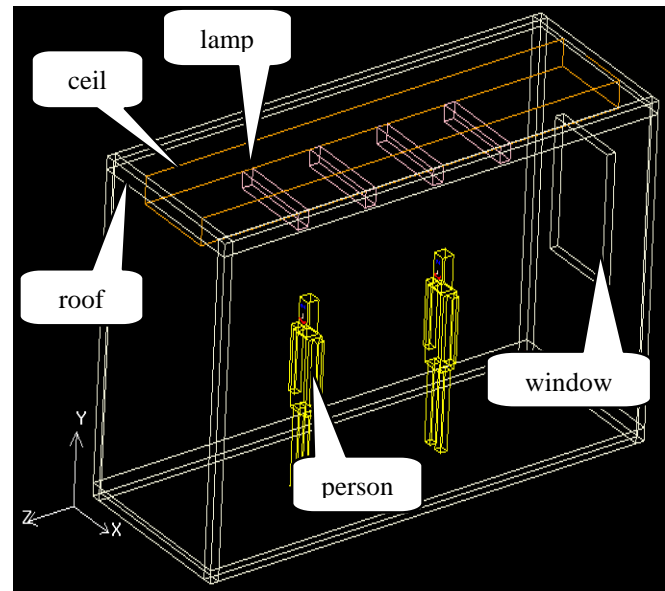

Figure 2. The diagram of physical model

\section{SIMULATION RESULTS AND THEIR ANALYSIS}

\section{A. The temperature distribution of the room}

- The average temperature of the room

Through the software that the model calculated and read the average temperature of the room .

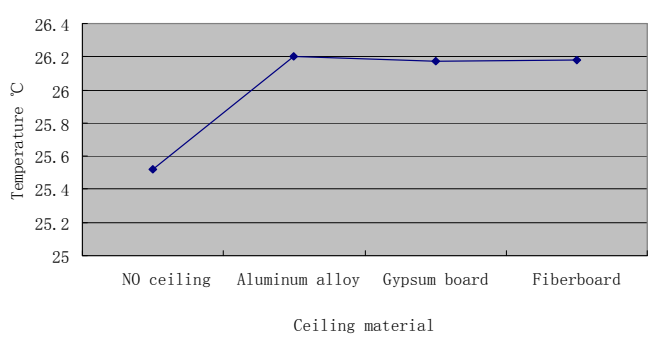

Figure 3. The average temperature of the room in different ceiling material

Through on the above tables and figures we can see that the average temperature of the room has ceiling increase than no ceiling, but the degree of increase is different. This is due to the radiative heat transfer between the ceiling material and the roof, while due to the thermal conductivity of the material itself, causing attenuation of the cold of radiation to the space below the ceiling. However, the maximum deviation of the average room temperature and $26^{\circ} \mathrm{C}$ indoor design requirements is $1.85 \%$, which meets the design requirements. So we can get the conclude that ceiling for the influence of the average temperature of the room is very small.

- The temperature distribution of the room in the vertical and horizontal direction

When the human body is standing, it is taken from the ground $1.7 \mathrm{~m}, 1.55 \mathrm{~m}, 0.9 \mathrm{~m}, 0.25 \mathrm{~m}$, and $0.15 \mathrm{~m}$, respectively on behalf of the head of the human body, shoulders, waist, knee, and ankle parts. In the window vertical center plane, take the horizontal distance from the outer windows were 1 $\mathrm{m}, 2 \mathrm{~m}, 3 \mathrm{~m}, 4 \mathrm{~m}, 5 \mathrm{~m}$ of five cross-section , and analyze the relevant parts of the human body's temperature.

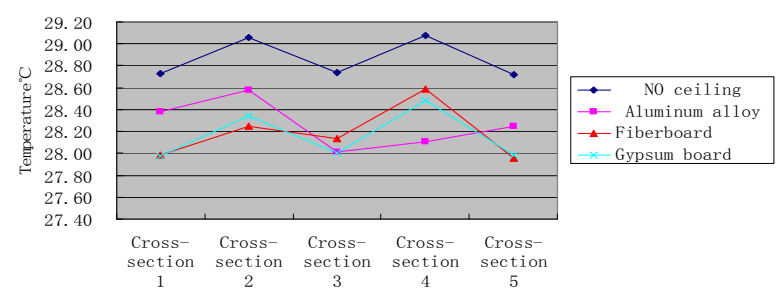

Figure 4. The temperature distribution of the different cross-section at the head

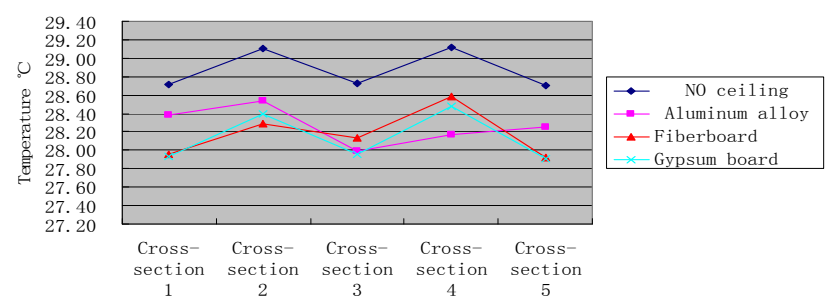

Figure 5. The temperature distribution of the different cross-section at shoulder

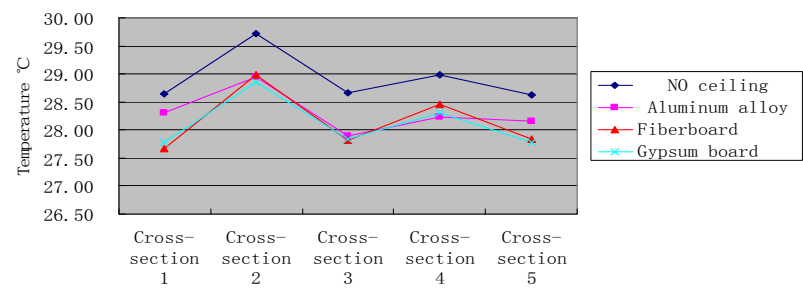

Figure 6. The temperature distribution of the different cross sections at the waist

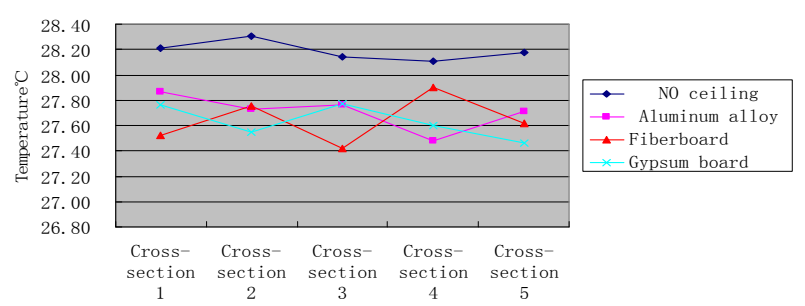

Figure 7. The temperature distribution of the different cross-section at the knee

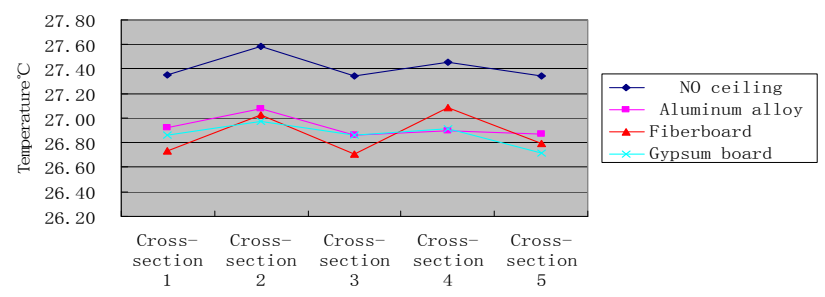

Figure 8. The temperature distribution of the different cross-section at the ankle 
As can be seen from the above line graph, the temperature in different parts of the cross-section 3 showed a downward trend. This is mainly due to section 3 is in the middle of the room along the longitudinal direction of the parts, but also in the middle of the two stationary body and the farther the distance to the human body, the human body in this section of the radiation is less heat, so the temperature is lower than other sections. At the same time because the lower roof to the laying of the coil, so the floor temperature is lower compared to the other wall temperature and foot temperature compared to other parts of body is lower in each section. The temperature values of the same part in different cross-section are fluctuant, but the volatility is little, within \pm $1^{\circ} \mathrm{C}$.

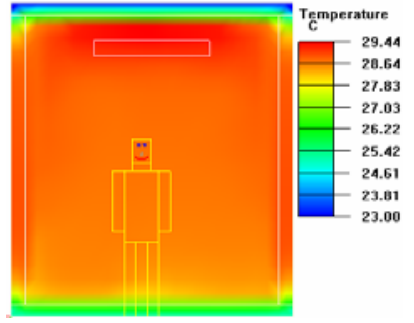

( 1 ) the temperature distribution figure when no ceiling

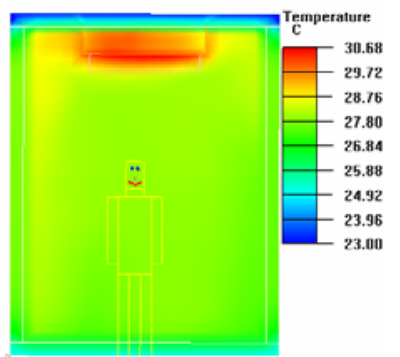

( 3 ) the temperature distribution figure when gypsum board is ceiling material

Figure 9. The temperature distribution figure at the direction of the width of the room in the longitudinal direction at the center of vertical surface parallel with the outer window room

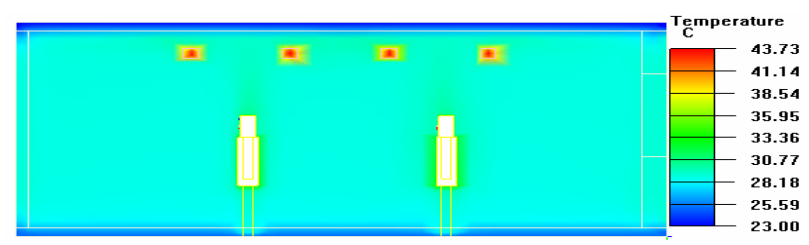

(1) The temperature distribution figure when no ceiling

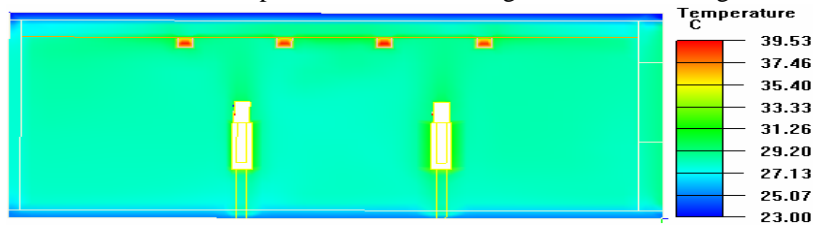

(2) The temperature distribution figure when aluminum alloy is ceiling material

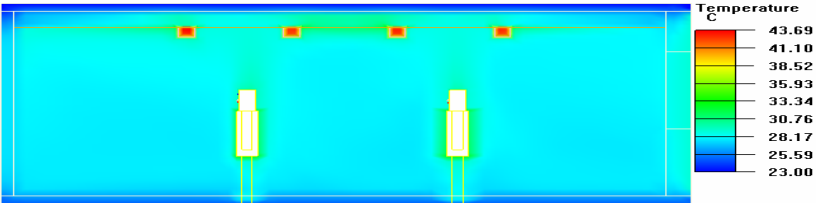

(3) The temperature distribution figure when gypsum board is ceiling material

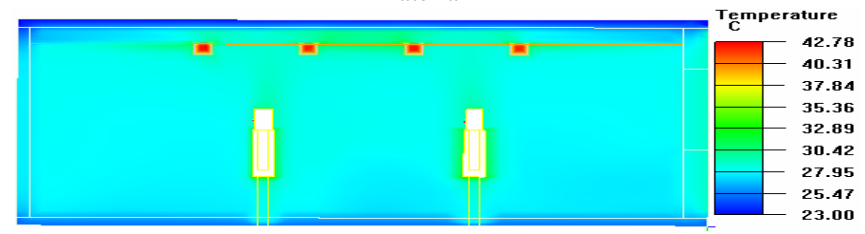

(4) The temperature distribution figure when fiberboard is ceiling material

Figure 10. The temperature distribution figure at the direction of the length of the room in the vertical plane coincident with the vertical center plane of the outer windows.

In the above two sets of temperature distribution graph , from the distribution of the color we can clearly see when there is no ceiling the room average temperature is the lowest, and the temperature distribution of each condition in the work area of the room is relatively uniform. In the vicinity of the human body and lamps due to its relatively high temperature so the heat radiation is relatively large and cause a localized temperature rise, but because of the different thermal conductivity and radiation performance of the each of the ceiling material, so that the amplitude of the local temperature rise is different.

\section{B. Analysis of the roof heat transfer performance}

- Ceiling temperature distribution and its uniformity

According to the actual situation, the height of the ceiling in the simulation from the ground is $2.6 \mathrm{~m}$; the net distance from roof to ceiling is $0.15 \mathrm{~m}$. The following is the temperature distribution of the ceiling plane:

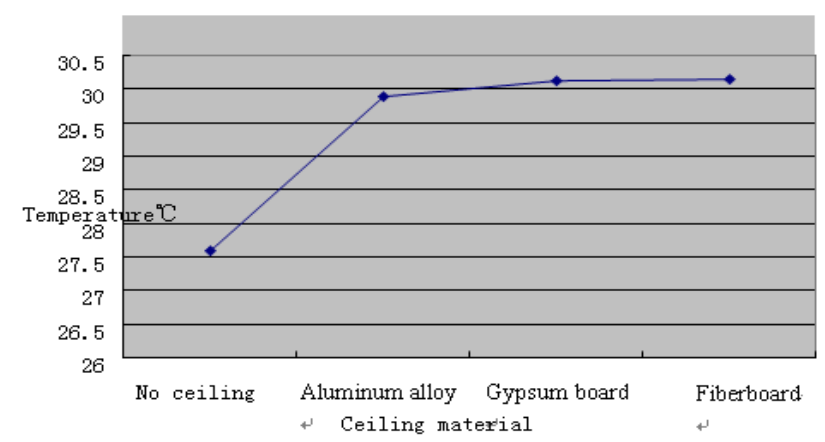

Figure 11. The temperature distribution figure at ceiling plane

By the above data can see that the average temperature of the ceiling plane is higher $2-3{ }^{\circ} \mathrm{C}$ than when no ceiling, which leads to the reduction in radiation heat transfer temperature difference, and from the aforementioned radiation heat formula can know, this will bring the attenuation of the heat exchange. The maximum temperature 
of the ceiling appears in the position of the lamp, but because of the different coefficient of thermal conductivity and emissivity of the ceiling materials, so the maximum value of the temperature is different.

- Analysis of the roof heat flux

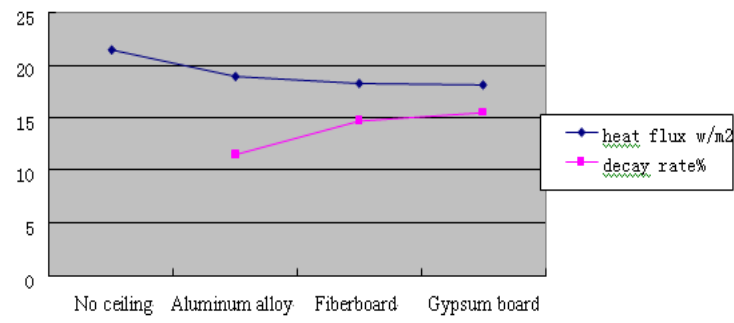

Figure 12. The roof heat flux

By the above data it can be seen that the additional ceiling cases the decay of the roof heat flux, but the decay rate is different. When ceiling material is aluminum alloy, the decay rate of roof heat flux is min, reaches $11.50 \%$; and when ceiling material is gypsum board; the decay rate of roof heat flux is max, reaches $15.52 \%$. This phenomenon is mainly caused by a different variety of the thermal conductivity of the ceiling material, the gradation, the absorption rate and the emission rate.

\section{CONCLUSIONS}

1. The maximum deviation of the average room temperature and $26{ }^{\circ} \mathrm{C}$ indoor design requirements is $1.85 \%$, which meets the design requirements .So we can get the conclude that ceiling for the influence of the average temperature of the room is very small.
2、When the room does not set a ceiling, the roof heat flux density is $21.39 \mathrm{~W} / \mathrm{m} 2$. When the ceiling material is aluminum alloy, the roof heat flux attenuation is minimum, is $11.50 \%$.

So in summary, under the premise of meeting the requirements of hanging lamps and hidding the pipeline within ceiling, we should try to use the big thermal conductivity of ceiling materials as roof radiant cooling room ceiling materials. In addition, we should consider the cost, interior decoration requirements.

\section{REFERENCES}

[1] Quanying Yan, Zhengxin Qi and Wei Wang. Research on the heattransfer process of the radiant ceiling cooling system. Building Energy \& Environment, 2004,23 (6)

[2] Chaoliang Lu,Rudong Chen. The Heat transfer capability of ceiling under different construction of the ceiling. Energy Technology, 2007,28 (6)

[3] Wen-hong Yu, Zhao Yang. Radiant cooling ceilings and dwelling house air-conditioning. Energy Conservation, 2005,6

[4] Renjie Deng, Lizhi Zhang and Qinghua Yin. Progress on chilled ceiling systems. Building Energy \& Environment, 2004,23 (5)

[5] [5]Fang Yang. Research and its application of metal radiant cooling ceiling. Hunan University, a master's degree thesis

[6] Yuding Qi,Guimei song. Reach of ceiling radiation heating and cooling. Architectural Society of China Building Energy Transmission Branch sixteenth Academic Exchange Conference

[7] Zhengxin Qi,Jinguo Bai. Discussion of radiant cooling by concrete ceiling. China Construction Heating\&Refrigration, 2002,(06)

[8] Long Xiao, Yonghong Wang. Radiative cooling calculation method based on the simulation of the ceiling. 2010 National HVAC Annual Conference 